\title{
A dinâmica do transporte marítimo de cabotagem e longo curso no Brasil: circulação do capital e modernizações
}

\author{
Márcio Rogério Silveira* \\ Nelson Fernandes Felipe Junior ${ }^{* *}$
}

\section{Resumo}

No artigo propõe-se realizar uma análise do transporte marítimo brasileiro (cabotagem e longo curso). A mobilidade, a acessibilidade e a integração nacional são intensificadas com o transporte de cabotagem, ao mesmo tempo em que há o beneficiamento, sobretudo, da indústria brasileira (petróleo e derivados para serem usados como matérias-primas). A articulação do Brasil com os demais países ocorre, principalmente, pelo transporte internacional (longo curso). Para o transporte marítimo são essenciais o meio físico (mar/oceano), o planejamento setorial, os investimentos infraestruturais e as estratégias logísticas das empresas. A modernização do setor portuário e marítimo brasileiro contribui para a expansão dos fluxos de mercadorias (exportações e importações) e intensifica a circulação e a reprodução do capital.

Palavras-chave: Transporte marítimo; Circulação do capital; Redes; Fluxos; Modernizações.

\footnotetext{
Doutor em Geografia pelo Programa de Pós-Graduação da FCT/UNESP, campus de Presidente Prudente. Professor da Graduação e da Pós-Graduação em Geografia da UFSC e da Pós-Graduação em Geografia da FCT/UNESP. Endereço eletrônico para contato: marcioourinhos@gmail.com

** Doutor em Geografia pelo Programa de Pós-Graduação da FCT/UNESP, campus de Presidente Prudente. Endereço eletrônico para contato: nelfelipejr@hotmail.com
}

Geosul, Florianópolis, v. 28, n. 55, p 7-29, jan./jun. 2013 
SILVEIRA, M.R. \& FELIPE JR., N.F. A dinâmica do transporte marítimo ...

Dynamics of maritime transport cabotage and long distance in Brazil: circulation of capital and upgrades

\section{Abstract}

In the article proposes to carry an analysis of brazilian maritime transport (cabotage and long distance). Mobility, accessibility and national integration are intensified with cabotage, while there is the improvement, especially in the brazilian industry (oil, oil products and others to be used as raw materials), as the articulation of Brazil with other countries occurs primarily by the international transport (long distance). For maritime transport are essential to the physical environment (sea/ocean), sectoral planning, infrastructural investments and logistics strategies of companies. The modernization of the brazilian port and maritime sector contributes to the expansion of flows of goods (exports and imports) and enhances circulation and reproduction of capital.

Key words: Maritime transport; Circulation of capital; Networks; Flows; Upgrades.

\section{Introdução}

A modernização do sistema de transportes facilita a mobilidade e a acessibilidade e reduz o tempo de deslocamento no espaço. A participação do Estado é fundamental para o desenvolvimento econômico, para o fomento do transporte marítimo e para a circulação e a mobilidade geográfica do capital. A ampliação da produção e a expansão dos transportes são fundamentais para a geração de empregos e renda, consequentemente, aumenta-se a demanda por bens duráveis e nãoduráveis (efeito multiplicador interno).

Com a reestruturação produtiva, as tecnologias ligadas à circulação, a grande capacidade dos navios cargueiros e a 
SILVEIRA, M.R. \& FELIPE JR., N.F. A dinâmica do transporte marítimo ...

otimização logística, têm-se intensas repercussões na produção e no comércio. Grandes quantidades de cargas, atualmente, podem ser transportadas em menos tempo e com custos mais baixos, aparecendo sucessivamente no mercado (reabastecimento rápido do estoque), não sendo necessário, portanto, a armazenagem em larga escala na forma de capital-mercadoria latente. Com o aprimoramento da logística e a expansão do transporte marítimo, o retorno do dinheiro aplicado ocorre em períodos mais curtos, de modo que parte da mercadoria se transforma continuamente em capital-dinheiro, enquanto a outra parte circula no espaço como capital-mercadoria em condições de ser comercializada.

O transporte marítimo não representa um fim em si mesmo, ou seja, é um meio de servir a outros objetivos e outras demandas. A atividade produtiva (indústria e agricultura) é dependente do transporte marítimo internacional para conquistar mercados externos (acumulação e reprodução acelerada do capital), ao passo que a cabotagem tem como objetivo principal subsidiar a cadeia de suprimentos interna (matérias-primas). O sistema de transportes e, em especial, o modal marítimo é, por um lado, um reflexo da economia regional/nacional e, por outro, um fator que impulsiona o desenvolvimento. $\mathrm{O}$ transporte marítimo de cargas é subsidiário à produção e, ao mesmo tempo, imprescindível para completar a rotatividade do capital.

\section{Transporte marítimo, circulação do capital e ciclos econômicos}

As redes, os fluxos, as inter-relações estabelecidas entre as diferentes empresas e a circulação do capital são intensificadas nos períodos de ascensão econômica e reduzidas nas fases recessivas (RANGEL, 1981; MIGLIOLI, 2004). O transporte marítimo possui sua dinâmica atrelada aos ciclos de expansão e retração da economia nacional (juglarianos) e mundial (Kondratieff), visto que há, respectivamente, impulso e diminuição das relações comerciais em escala global. 
SILVEIRA, M.R. \& FELIPE JR., N.F. A dinâmica do transporte marítimo ...

Os ciclos de Kondratieff representam períodos de cinquenta anos, sendo vinte e cinco anos de ascensão e vinte e cinco anos de recessão econômica internacional. Em relação aos movimentos cíclicos internos de média duração (ciclos juglarianos), estes variam entre sete e onze anos e iniciaram com a industrialização brasileira (terceira dualidade).

O Estado possui papel relevante no que tange ao incremento (ou não) do processo de circulação do capital. A expansão das infraestruturas de transportes e energia (destaque para o fomento da intermodalidade e do transporte marítimo), os incentivos creditícios e tributários e as políticas setoriais são importantes para acelerar a rotatividade do capital (repercussões não apenas na distribuição dos bens, mas na produção e na instalação de unidades fabris no território) (RANGEL, 2005). O processo de acumulação e a mobilidade geográfica do capital são impulsionados, em maior ou menor medida, pela atuação do poder público e pela política econômica adotada.

A organização do espaço, sob o capitalismo, está relacionada às revoluções industriais e nos transportes, às fases positivas e negativas da economia e às reestruturações tecnológicas (MAMIGONIAN, 1999). As dualidades brasileiras são caracterizadas por diferentes processos de substituição de importações e influenciadas pelos ciclos de Kondratieff (longos) e Juglar (médios) - estes últimos iniciam-se com o Governo Vargas. Enquanto a substituição de importações da primeira dualidade (1815/1822-1888/1889) teve a forma de diversificação da produção para autoconsumo na fazenda escravista, a da segunda dualidade (1888/1889-1930) surge, dominantemente, como produção mercantil pré-industrial (artesanal) e a da terceira dualidade (1930-1985) assume, predominantemente, a forma de artigos industriais (RANGEL, 2005).

Segundo Rangel (1981), a economia brasileira é pautada na complexidade e na dualidade. Assim, é necessário compreender as etapas do desenvolvimento brasileiro a partir da coexistência do comunismo primitivo, do feudalismo e do capitalismo em todas as suas etapas (das atrasadas às modernas), além de um capitalismo conduzido pelo Estado a partir de 1930. A economia nacional - 
SILVEIRA, M.R. \& FELIPE JR., N.F. A dinâmica do transporte marítimo ... enquanto complementar à dos países centrais - rege-se, basicamente, pelas relações internas e externas de produção, sendo influenciada pelos ciclos de Kondratieff (longos) e Juglar (médios). A passagem de uma dualidade para outra altera o pacto de poder existente, contudo, no Brasil, essas "alianças" sempre tiveram uma característica estritamente burguesa.

Nos momentos depressivos, há um enfraquecimento do comércio exterior, isto é, o Brasil reduz sua participação na divisão internacional do trabalho. O país, durante as dualidades, voltava sua economia "para dentro", promovendo um processo substitutivo de importações, responsável por movimentar a economia interna. Nas épocas de prosperidade econômica internacional, o Brasil direcionavase mais "para fora", aumentando a produção e os fluxos de exportações, que se tornavam as bases da economia nacional (RANGEL, 2005).

Nos momentos de expansão econômica, disponibiliza-se uma grande quantidade de dinheiro para empréstimo nos bancos públicos e privados, intensificam-se os investimentos privados na produção industrial e agrícola, há maior demanda por transporte marítimo, incrementam-se as trocas, potencializam-se as redes entre firmas, há maior geração de empregos e renda, aumenta o consumo de bens duráveis e não-duráveis e potencializam-se as conexões entre diferentes regiões e países. Contudo, nos períodos recessivos surgem gargalos no processo de circulação do capital, o crédito muitas vezes é reduzido (tanto ao capitalista quanto ao consumidor), há queda na atividade produtiva (sobretudo industrial), diminui a demanda pelo transporte hidroviário (mitigação dos fluxos de cabotagem e internacionais), as interações espaciais se arrefecem e há redução do consumo e das trocas (maior protecionismo), gerando, consequentemente, repercussões negativas à economia e à sociedade (RANGEL, 1981; MIGLIOLI, 2004).

\section{O transporte marítimo de cabotagem e longo curso no Brasil}

$\mathrm{O}$ transporte marítimo de cabotagem articula portos localizados em um mesmo país, todavia, no Brasil ainda é 
SILVEIRA, M.R. \& FELIPE JR., N.F. A dinâmica do transporte marítimo ...

incipiente esta modalidade de transporte em comparação ao modal rodoviário. A grande dimensão territorial brasileira e sua extensa costa litorânea (mais de 8 mil quilômetros) criam condições propícias à cabotagem, porém há um predomínio exacerbado do transporte de cargas por caminhões (ainda que este seja importante para garantir o sistema "porta a porta"). A cabotagem no Brasil é realizada, principalmente, entre portos distantes geograficamente, caso, por exemplo, da articulação entre Santos/SP e Rio Grande/RS e Santos/SP e Belém/PA.

Nas décadas de 1950, 1960 e 1970 o transporte de cabotagem era forte no Brasil, mantido com base na reserva de mercado e na existência de empresas estatais operando no setor, fato que criava demanda na indústria naval nacional. Lloyd Brasileiro e Costeira (estatais), juntamente com a Aliança e a Netumar (cabotagem e longo curso) - estas duas últimas privadas eram as principais e atuavam sob o regime de concessão. Entretanto, na década de 1990, a cabotagem foi desmantelada com a desregulamentação do setor e a política neoliberal.

Fomentar a cabotagem no Brasil é importante para racionalizar o setor de transportes no país, mitigar o Custo Brasil, aumentar a competitividade dos produtos nacionais, reduzir o preço final dos bens e arrefecer os congestionamentos de caminhões nos acessos dos principais portos marítimos brasileiros, caso do Porto de Santos/SP. Além disso, a expansão da cabotagem gera demanda na indústria naval (construção de navios) e nos armadores nacionais, contribuindo, assim, com a geração de empregos e renda.

Como estratégia para fomentar a cabotagem no Brasil, é importante viabilizar o carreamento de recursos ociosos para o setor, bem como aplicar o modelo ideal de concessão de serviços públicos à iniciativa privada, ou seja, de acordo com a proposta rangeliana (Projeto de Lei n. 2.569/89) e diferentemente da lei geral de concessões (Lei n. 8.987/95) - Lei Fernando Henrique Cardoso. A transferência de recursos ociosos para a cabotagem (antiocioso) deve ocorrer a partir de uma estrutura legal e de um mecanismo de intermediação financeira que estimulem investimentos no setor, 
SILVEIRA, M.R. \& FELIPE JR., N.F. A dinâmica do transporte marítimo ...

evitando-se que tais recursos sejam destinados ao sistema financeiro e a segmentos superinvestidos (RANGEL, 2005). Garantir a reserva de mercado, aumentar as inversões públicas e privadas, expandir o crédito e a demanda no setor (a partir, por exemplo, da criação de empresas estatais de cabotagem) e incentivos fiscais, são ações que contribuem para alavancar a cabotagem no país (tabela 1), sobretudo, pelo fato da possibilidade de intensificação da exploração das reservas do Pré-Sal nas próximas décadas.

Tabela 1: Transporte de cabotagem no Brasil (1997-2011) (milhões de toneladas).

\begin{tabular}{c|c|c|c|c}
\hline Anos & Granéis sólidos & Granéis líquidos & Carga geral & Total \\
\hline 1997 & 25,4 & 79,3 & 1,1 & $\mathbf{1 0 5 , 9}$ \\
\hline 1998 & 15,4 & 100,2 & 1,8 & $\mathbf{1 1 7 , 3}$ \\
\hline 1999 & 22,6 & 97,6 & 2,2 & $\mathbf{1 2 2 , 5}$ \\
\hline 2000 & 27,1 & 104,2 & 3,3 & $\mathbf{1 3 4 , 7}$ \\
\hline 2001 & 24,8 & 107,9 & 4,6 & $\mathbf{1 3 7 , 3}$ \\
\hline 2002 & 24,0 & 106,9 & 6,2 & $\mathbf{1 3 7 , 0}$ \\
\hline 2003 & 27,4 & 111,4 & 7,1 & $\mathbf{1 4 5 , 9}$ \\
\hline 2004 & 28,2 & 111,5 & 8,7 & $\mathbf{1 4 8 , 4}$ \\
\hline 2005 & 28,4 & 112,5 & 9,2 & $\mathbf{1 5 0 , 1}$ \\
\hline 2006 & 33,1 & 116,2 & 14,2 & $\mathbf{1 6 3 , 5}$ \\
\hline 2007 & 31,7 & 122,8 & 14,0 & $\mathbf{1 6 8 , 5}$ \\
\hline 2008 & 32,2 & 125,7 & 14,9 & $\mathbf{1 7 2 , 8}$ \\
\hline 2009 & 31,8 & 130,9 & 13,1 & $\mathbf{1 7 5 , 8}$ \\
\hline 2010 & 32,4 & 139,8 & 15,8 & $\mathbf{1 8 8 , 0}$ \\
\hline 2011 & 34,1 & 142,6 & 16,9 & $\mathbf{1 9 3 , 6}$ \\
\hline
\end{tabular}

Fonte: Agência Nacional de Transportes Aquaviários (ANTAQ), 2012.

Exceto a pequena variação de 2002 em relação a 2001, o transporte de cabotagem no Brasil cresceu ao longo do período analisado, com destaque ao transporte de granéis líquidos (tabela 1). No Porto de Santos/SP se encontra o maior terminal privado de granéis líquidos do Brasil, e o Terminal Almirante Barroso (TEBAR), da Petrobras (em São Sebastião/SP), é um dos maiores do Hemisfério Sul (COMPANHIA DOCAS DE SÃO SEBASTIÃO; CODESP, 2011). 
SILVEIRA, M.R. \& FELIPE JR., N.F. A dinâmica do transporte marítimo ...

$\mathrm{O}$ transporte de cabotagem apresentou relativa expansão nos últimos anos, mas a utilização do modal ainda é pequena no país. $\mathrm{O}$ montante escoado pela cabotagem, atualmente, representa apenas $10 \%$ da movimentação total da Santos Brasil ${ }^{1}$ (terminais em Santos/SP, Imbituba/SC e Vila do Conde/PA) e da APM Terminals ${ }^{2}$ (terminal no Porto de Itajaí/SC). Os principais fatores que prejudicam o avanço da cabotagem no Brasil são: o predomínio do modal rodoviário (infraestruturas, meios de transportes, tecnologias e sistemas de normas que formam uma estrutura rugosa e consolidada que mantém o domínio do setor), conexões intermodais precárias, rodovias pedagiadas em condições adequadas (são vantajosas às indústrias exportadoras de bens de alto valor agregado), óleo diesel subsidiado, possibilidade do sistema "porta a porta" pelo caminhão e as empresas de navegação preferem investir, muitas vezes, no longo curso em detrimento da cabotagem (mais lucrativo).

Não existem terminais especializados no transporte de cabotagem nos principais portos do Brasil, caso, por exemplo, de Santos/SP, Paranaguá/PR, Itajaí/SC e Rio Grande/RS, visto que há, em geral, uma preferência pelo transporte de longo curso, em decorrência de algumas vantagens, tais como: a possibilidade dos armadores realizarem mais escalas em portos de diferentes países, navios carregados com produtos de importação (cargas de retorno), os fretes se tornam mais baratos (devido às maiores distâncias percorridas) e utilização de navios maiores e com grande capacidade de escoamento de cargas (CODESP, 2011).

O sistema marítimo brasileiro é muito concentrado nos portos do Sul e do Sudeste, isto é, há uma concentração dos fluxos internacionais de cargas nestas duas macrorregiões do país (tabela

${ }^{1}$ A Santos Brasil é um dos principais operadores portuários do país. O terminal localizado no complexo santista (que compreende o Terminal de Contêineres - TECON e o Terminal de Exportação de Veículos TEV) é o maior da América do Sul.

2 A APM Terminals é uma empresa do grupo A.P. Moller Maersk (Dinamarca) que se dedica às operações portuárias. 
SILVEIRA, M.R. \& FELIPE JR., N.F. A dinâmica do transporte marítimo ...

2). O Porto de Santos/SP se destaca na movimentação de bens industrializados e contêineres (maior valor agregado), sendo um ponto nodal que atende a demanda, sobretudo, do Estado de São Paulo e do Centro-Oeste do país.

Tabela 2: Principais portos brasileiros no valor total movimentado (2010 e 2011).

\begin{tabular}{|c|c|c|c|c|c|}
\hline Anos & Posição & Portos & $\begin{array}{l}\text { Principais } \\
\text { cargas }\end{array}$ & $\begin{array}{l}\text { Valor total } \\
\text { (em dólares) }\end{array}$ & $\begin{array}{c}\text { Regiões e países } \\
\text { de origem das } \\
\text { cargas }\end{array}$ \\
\hline \multirow{6}{*}{2010} & $1^{o}$ & Santos/SP & $\begin{array}{l}\text { Grãos, farelos, } \\
\text { químicos, } \\
\text { industriais } \\
\end{array}$ & 95,8 bilhões & $\begin{array}{c}\text { Centro-Oeste, } \\
\text { Sudeste, Bolívia, } \\
\text { Paraguai }\end{array}$ \\
\hline & $2^{\circ}$ & Vitória/ES & $\begin{array}{l}\text { Minérios, grãos } \\
\text { industriais }\end{array}$ & 33,1 bilhões & $\begin{array}{c}\text { Centro-Oeste, } \\
\text { Sudeste, Nordeste }\end{array}$ \\
\hline & $3^{\circ}$ & Itaguaí/RJ & $\begin{array}{c}\text { Químicos, } \\
\text { industriais, } \\
\text { offshore } \\
\end{array}$ & 25,1 bilhões & Sudeste \\
\hline & $4^{\circ}$ & Paranaguá/PR & $\begin{array}{c}\text { Grãos, farelos, } \\
\text { madeira, } \\
\text { industriais }\end{array}$ & 24,4 bilhões & Sul e Paraguai \\
\hline & $5^{\circ}$ & Rio de Janeiro/RJ & $\begin{array}{l}\text { Químicos, } \\
\text { industriais } \\
\end{array}$ & 16,3 bilhões & Sudeste \\
\hline & $6^{\circ}$ & Rio Grande/RS & $\begin{array}{l}\text { Grãos, farelos, } \\
\text { industriais }\end{array}$ & 15,8 bilhões & Sul \\
\hline \multirow{6}{*}{2011} & $1^{\mathrm{o}}$ & Santos/SP & $\begin{array}{l}\text { Grãos, farelos, } \\
\text { químicos, } \\
\text { industriais }\end{array}$ & 118,2 bilhões & $\begin{array}{c}\text { Centro-Oeste, } \\
\text { Sudeste, Bolívia, } \\
\text { Paraguai }\end{array}$ \\
\hline & $2^{\circ}$ & Vitória/ES & $\begin{array}{l}\text { Minérios, grãos } \\
\text { industriais }\end{array}$ & 43,2 bilhões & $\begin{array}{c}\text { Centro-Oeste, } \\
\text { Sudeste, Nordeste }\end{array}$ \\
\hline & $3^{\circ}$ & Itaguaí/RJ & $\begin{array}{c}\text { Químicos, } \\
\text { industriais, } \\
\text { offshore } \\
\end{array}$ & 35,1 bilhões & Sudeste \\
\hline & $4^{\circ}$ & Paranaguá/PR & $\begin{array}{l}\text { Grãos, farelos, } \\
\text { madeira, } \\
\text { industriais }\end{array}$ & 32,4 bilhões & Sul e Paraguai \\
\hline & $5^{\circ}$ & São Luís/MA & $\begin{array}{l}\text { Químicos, } \\
\text { industriais }\end{array}$ & 23,2 bilhões & $\begin{array}{c}\text { Norte, Nordeste e } \\
\text { Centro-Oeste }\end{array}$ \\
\hline & $6^{\circ}$ & Rio Grande/RS & $\begin{array}{l}\text { Grãos, farelos, } \\
\text { industriais }\end{array}$ & 20,1 bilhões & Sul \\
\hline
\end{tabular}

Fonte: Agência Nacional de Transportes Aquaviários (ANTAQ); Companhia Docas do Estado de São Paulo (CODESP); Ministério do Desenvolvimento, Indústria e Comércio Exterior - Secretaria de Comércio Exterior (SECEX); Ministério dos Transportes, 2012. 
SILVEIRA, M.R. \& FELIPE JR., N.F. A dinâmica do transporte marítimo ...

Os principais portos marítimos brasileiros no valor total movimentado são: Santos/SP, Vitória/ES, Itaguaí/RJ, Paranaguá/PR, São Luís/MA, Rio Grande/RS e Rio de Janeiro/RJ. A dinâmica econômica do Centro-Sul do país (produção e fluxos de mercadorias) gera, consequentemente, uma significativa demanda pelos portos (tabela 2). Os complexos portuários do Sul e do Sudeste se destacam na movimentação de cargas e na balança comercial brasileira (tabela 3). Estes representam mais de $70 \%$ de todo comércio exterior brasileiro e, no caso das exportações de produtos industrializados, são responsáveis por, aproximadamente, 90\% do total nacional (SECEX, 2011).

A construção de infraestruturas, sobretudo, nas regiões menos dinâmicas, é um fator imprescindível ao efeito multiplicador interno, gerando repercussões positivas na economia, na sociedade e nas interações espaciais. O Estado - a partir do planejamento - tem a responsabilidade de reduzir as disparidades inter-regionais para possibilitar melhores condições de vida à população (RANGEL, 2005). 
SILVEIRA, M.R. \& FELIPE JR., N.F. A dinâmica do transporte marítimo ...

Tabela 3: Comparativo de movimentação de cargas, contêineres e navios em diversos portos e terminais privados brasileiros (2008-2011).

\begin{tabular}{|c|c|c|c|c|c|}
\hline $\begin{array}{c}\text { Portos / } \\
\text { terminais }\end{array}$ & Movimentação & 2008 & 2009 & 2010 & 2011 \\
\hline \multirow{3}{*}{ Santos/SP } & $\begin{array}{l}\text { Total geral de cargas (em } \\
\text { toneladas) }\end{array}$ & 81.058 .951 & 83.194 .129 & 96.025 .258 & 97.170 .308 \\
\hline & Contêineres (em unidades) & 1.743 .412 & 1.471 .367 & 1.762 .205 & 1.915 .292 \\
\hline & Navios (em unidades) & 5.918 & 5.731 & 5.748 & 5.874 \\
\hline \multirow{3}{*}{ São Sebastião/SP } & $\begin{array}{l}\text { Total geral de cargas (em } \\
\text { toneladas) }\end{array}$ & 822.281 & 518.375 & 653.425 & 663.471 \\
\hline & Contêineres (em unidades) & 78 & 543 & - & - \\
\hline & Navios (em unidades) & - & - & 53 & 59 \\
\hline \multirow{3}{*}{ Paranaguá/PR } & $\begin{array}{l}\text { Total geral de cargas (em } \\
\text { toneladas) }\end{array}$ & 33.000 .000 & 31.000 .000 & 38.000 .000 & 39.460 .000 \\
\hline & Contêineres (em unidades) & 310.462 & 234.074 & 320.736 & 334.621 \\
\hline & Navios (em unidades) & 1.736 & 1.540 & 2.297 & 2.346 \\
\hline \multirow{3}{*}{ Itajaí/SC } & $\begin{array}{l}\text { Total geral de cargas (em } \\
\text { toneladas) }\end{array}$ & 7.008 .621 & 6.139 .341 & 9.899 .781 & 10.446 .720 \\
\hline & Contêineres (em unidades) & 395.176 & 346.479 & 566.434 & 594.486 \\
\hline & Navios (em unidades) & 1.007 & 1.020 & 1.251 & 1.194 \\
\hline \multirow{3}{*}{$\begin{array}{l}\text { São Francisco do } \\
\text { Sul/SC }\end{array}$} & $\begin{array}{l}\text { Total geral de cargas (em } \\
\text { toneladas) }\end{array}$ & 8.337 .264 & 7.554 .114 & 9.618 .055 & 9.874 .610 \\
\hline & Contêineres (em unidades) & 53.094 & 51.487 & 54.726 & 55.281 \\
\hline & Navios (em unidades) & 807 & 843 & 726 & 703 \\
\hline \multirow{3}{*}{ Imbituba/SC** } & $\begin{array}{l}\text { Total geral de cargas (em } \\
\text { toneladas) }\end{array}$ & 1.839 .916 & 1.871 .967 & 1.911 .104 & 2.311 .731 \\
\hline & Contêineres (em unidades) & 8.235 & 7.831 & 9.457 & 9.994 \\
\hline & Navios (em unidades) & 165 & 195 & 196 & 192 \\
\hline \multirow{3}{*}{ Navegantes/SC** } & $\begin{array}{l}\text { Total geral de cargas (em } \\
\text { toneladas) }\end{array}$ & 3.789 .241 & 4.208 .647 & 5.987 .197 & 5.817 .988 \\
\hline & Contêineres (em unidades) & 136.734 & 245.982 & 348.920 & 392.570 \\
\hline & Navios (em unidades) & 302 & 619 & 616 & 374 \\
\hline \multirow[t]{3}{*}{ Itapoá/SC*** } & $\begin{array}{l}\text { Total geral de cargas (em } \\
\text { toneladas) }\end{array}$ & - & - & - & - \\
\hline & Contêineres (em unidades) & - & - & - & 55.000 \\
\hline & Navios (em unidades) & - & - & - & 105 \\
\hline
\end{tabular}

* O terminal da Santos Brasil, em Imbituba/SC, iniciou suas operações em 2008.

** O terminal da Portonave (Navegantes/SC) iniciou suas atividades em outubro de $2007 \mathrm{e}$ possui dados a partir de 2008.

*** O terminal de Itapoá/SC iniciou suas atividades em junho de 2011.

Fonte: Autoridades Portuárias; Companhias Docas, 2012. 
SILVEIRA, M.R. \& FELIPE JR., N.F. A dinâmica do transporte marítimo ...

O Porto de Santos/SP é responsável por, aproximadamente, um quarto da balança comercial nacional, sendo seguido por outros portos do Sul e do Sudeste, fato que elucida a dinâmica da "região concentrada" 3 . Com o aumento da participação do capital privado, sobretudo, na última década, houve uma expansão significativa da movimentação de cargas conteinerizadas e não-conteinerizadas no Brasil (tabela 3).

Nos últimos anos, mesmo sem haver grandes rupturas, houve uma recuperação da economia nacional, com base na expansão do crédito, nos investimentos em fixos (Programa de Aceleração do Crescimento - PAC) e nas parcerias comerciais SulSul. Estas ações, com base no planejamento e nos gastos públicos, criaram condições para elevação dos fluxos marítimos de mercadorias (tabela 4).

Entre os anos de 2003 e 2008, houve um grande crescimento do volume total de cargas movimentadas no sistema marítimo brasileiro, todavia, em 2009, devido à crise internacional, tem-se uma queda. Em 2010 e 2011, há uma recuperação da movimentação de todos os tipos de cargas (com ênfase às importações), fato que elucida o incremento da demanda interna (tabela 4). Nesse sentido, destacam-se os fluxos de longo curso, responsáveis pelas trocas do Brasil com outros países (tabela 5).

3 Santos (2002), com base nas marcantes heterogeneidades que caracterizam o território nacional, cria a denominação "região concentrada", pois é em grande parte do Centro-Sul do país que se concentram a população brasileira, as infraestruturas, as atividades econômicas, as movimentações e aplicações financeiras, a gestão do grande capital privado nacional e estrangeiro, a criação das leis que regem a sociedade, assim como as políticas adotadas pelo Estado. 
SILVEIRA, M.R. \& FELIPE JR., N.F. A dinâmica do transporte marítimo ...

Tabela 4: Dinâmica do volume de cargas movimentadas (toneladas métricas)* no sistema marítimo brasileiro (1991 e 2000-2011).

\begin{tabular}{c|c|c|c|c|c}
\hline Anos & Sólidos & Líquidos & $\begin{array}{c}\text { Carga geral } \\
\text { conteinerizada }\end{array}$ & $\begin{array}{c}\text { Carga geral não- } \\
\text { conteinerizada }\end{array}$ & Total \\
\hline 1991 & 120.371 & 98.726 & 10.278 & 15.649 & $\mathbf{2 4 5 . 0 2 4}$ \\
\hline 2000 & 281.292 & 154.556 & 25.066 & 23.747 & $\mathbf{4 8 4 . 6 6 1}$ \\
\hline 2001 & 289.265 & 163.987 & 29.728 & 23.227 & $\mathbf{5 0 6 . 2 0 7}$ \\
\hline 2002 & 301.972 & 163.135 & 35.229 & 28.668 & $\mathbf{5 2 9 . 0 0 4}$ \\
\hline 2003 & 336.276 & 161.886 & 41.672 & 30.956 & $\mathbf{5 7 0 . 7 9 0}$ \\
\hline 2004 & 369.611 & 166.555 & 50.476 & 34.078 & $\mathbf{6 2 0 . 7 2 0}$ \\
\hline 2005 & 392.904 & 163.717 & 54.963 & 37.834 & $\mathbf{6 4 9 . 4 1 8}$ \\
\hline 2006 & 415.728 & 175.541 & 63.338 & 38.226 & $\mathbf{6 9 2 . 8 3 3}$ \\
\hline 2007 & 457.435 & 194.599 & 68.045 & 34.637 & $\mathbf{7 5 4 . 7 1 7}$ \\
\hline 2008 & 460.184 & 195.637 & 73.248 & 39.254 & $\mathbf{7 6 8 . 3 2 4}$ \\
\hline 2009 & 432.985 & 197.935 & 65.394 & 36.617 & $\mathbf{7 3 2 . 9 3 1}$ \\
\hline 2010 & 505.887 & 208.457 & 76.894 & 42.644 & $\mathbf{8 3 3 . 8 8 2}$ \\
\hline 2011 & 543.100 & 212.300 & 84.700 & 45.900 & $\mathbf{8 8 6 . 0 0 0}$ \\
\hline
\end{tabular}

* 1 tonelada métrica é equivalente a $1.000 \mathrm{~kg}$.

Fonte: Agência Nacional de Transportes Aquaviários (ANTAQ), 2012.

Entre 2000 e 2008, tem-se um aumento do total de mercadorias movimentadas no transporte marítimo de longo curso, com destaque ao incremento das exportações nacionais. Não obstante, em 2009, há uma queda nas importações, nas exportações e no total movimentado, em decorrência da crise internacional. Não houve uma redução mais expressiva das exportações devido à diversificação das parcerias comerciais realizada nos últimos anos (fomento das trocas Sul-Sul). Em 2010 e 2011, houve crescimento das exportações, das importações e da movimentação total (tabela 5), contudo, é fundamental que o poder público crie estratégias para estimular a substituição de importações (beneficiando setores estratégicos da indústria nacional e a geração de empregos e renda) e ainda evitar a valorização do Real (controle cambial a favor dos interesses nacionais) como forma de reduzir as importações e elevar as exportações. 
SILVEIRA, M.R. \& FELIPE JR., N.F. A dinâmica do transporte marítimo ...

Tabela 5: Dinâmica da movimentação de cargas no transporte marítimo de longo curso nos portos públicos e terminais privados brasileiros entre 2000 e 2011 (em toneladas).

\begin{tabular}{c|c|c|c}
\hline Anos & Importação & Exportação & Total \\
\hline 2000 & 87.188 .722 & 244.929 .929 & $\mathbf{3 3 2 . 1 1 8 . 6 5 1}$ \\
\hline 2001 & 88.561 .904 & 258.967 .816 & $\mathbf{3 4 7 . 5 2 9 . 7 2 0}$ \\
\hline 2002 & 85.013 .102 & 285.769 .836 & $\mathbf{3 7 0 . 7 8 2 . 9 3 8}$ \\
\hline 2003 & 87.715 .381 & 313.880 .887 & $\mathbf{4 0 1 . 5 9 6 . 2 6 8}$ \\
\hline 2004 & 95.547 .924 & 351.588 .297 & $\mathbf{4 4 7 . 1 3 6 . 2 2 1}$ \\
\hline 2005 & 82.974 .736 & 390.082 .685 & $\mathbf{4 7 3 . 0 5 7 . 4 2 1}$ \\
\hline 2006 & 90.010 .736 & 412.908 .583 & $\mathbf{5 0 2 . 9 1 9 . 3 1 9}$ \\
\hline 2007 & 111.208 .520 & 447.837 .373 & $\mathbf{5 5 9 . 0 4 5 . 8 9 3}$ \\
\hline 2008 & 114.511 .963 & 453.892 .926 & $\mathbf{5 6 8 . 4 0 4 . 8 8 9}$ \\
\hline 2009 & 91.505 .738 & 439.771 .431 & $\mathbf{5 3 1 . 2 7 7 . 1 6 9}$ \\
\hline 2010 & 126.803 .596 & 489.594 .125 & $\mathbf{6 1 6 . 3 9 7 . 7 2 1}$ \\
\hline 2011 & 143.300 .000 & 514.700 .000 & $\mathbf{6 5 8 . 0 0 0 . 0 0 0}$ \\
\hline
\end{tabular}

Fonte: Agência Nacional de Transportes Aquaviários (ANTAQ), 2012.

A maior diversificação dos parceiros comerciais do Brasil é uma importante medida anticíclica. Diante disso, destaca-se o grande crescimento das importações e exportações brasileiras para a Ásia e, em especial, para a China (mapa 1). Não obstante, o Brasil exporta, sobretudo, bens primários para o país asiático (mais de $70 \%$ das vendas externas se concentram em petróleo e derivados, soja e minério de ferro), sendo prejudicial ao fomento do setor secundário da economia nacional.

Tanto na origem das importações quanto no destino das exportações nacionais, em primeiro lugar, está a Ásia. Merecem ênfase também a América Latina e o Caribe, assim como o Mercosul, pois são importantes mercados consumidores para os bens de consumo duráveis e não-duráveis brasileiros, fato que fomenta o efeito multiplicador interno (mapa 1). Como resultado da crise internacional e dos acordos estabelecidos com nações africanas e do Oriente Médio nos últimos anos, por um lado, tem-se uma queda na participação dos países desenvolvidos nas trocas com o Brasil e, por outro, aumentou a importância dos países periféricos. 
SILVEIRA, M.R. \& FELIPE JR., N.F. A dinâmica do transporte marítimo ...

Mapa 1: Principais grupos de países e blocos econômicos de origem das importações e de destino das exportações do Brasil em 2011.

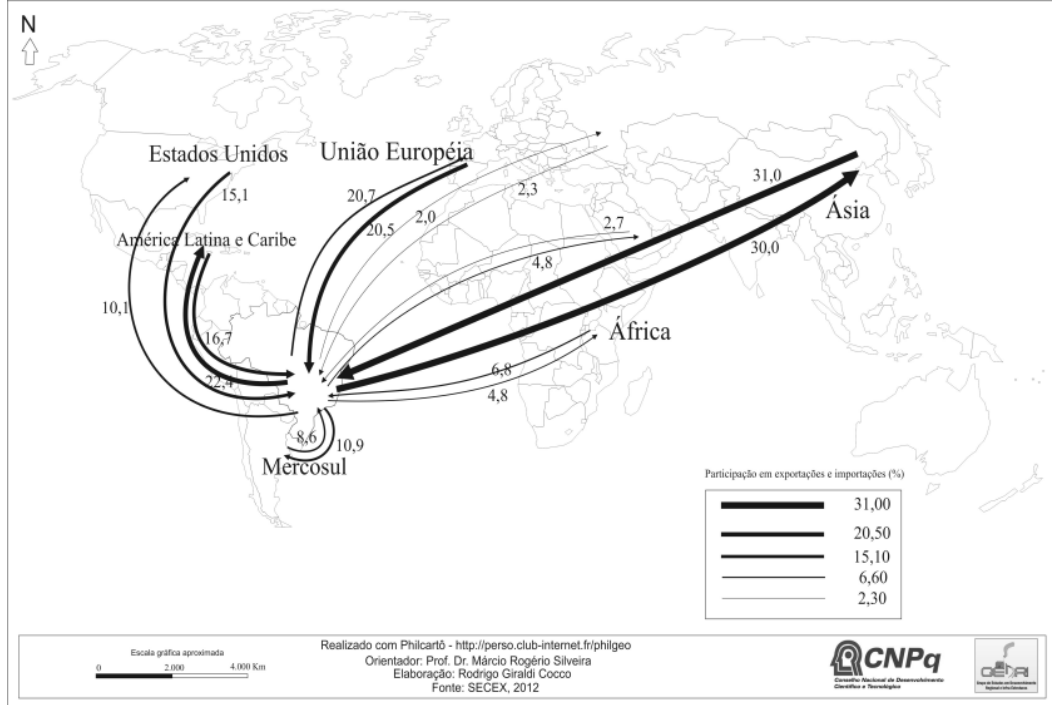

\section{As transformações e modernizações no setor marítimo brasileiro}

O sistema marítimo brasileiro é caracterizado pela desregulamentação, bem como pela existência de oligopólio estrangeiro ${ }^{4}$, sendo intensificado pela legislação neoliberal criada na década de 1990 (Lei 8.630/93), mitigando a reserva de mercado para os armadores nacionais e abrindo o setor para o grande capital estrangeiro. As concessões ligadas ao setor marítimo refletem a frágil atuação do Estado, das Companhias Docas, das Autoridades

${ }^{4}$ Os principais armadores que atuam nos portos brasileiros são: Hamburg Süd (Alemanha), Maersk (Dinamarca), Mediterranean Shipping Company (MSC) (Itália/Suíça), Aliança (pertence à Hamburg Süd, Alemanha), CMA/CGM (França), Cia Sudamericana de Vapores (CSAV) (Chile), Mitsui/OSK Lines (Japão), Cosco (China), Evergreen (Taiwan) e China Shipping (China). 
SILVEIRA, M.R. \& FELIPE JR., N.F. A dinâmica do transporte marítimo ...

Portuárias, da Secretaria de Portos (SEP) e da Agência Nacional de Transportes Aquaviários (ANTAQ) na imposição de metas às concessionárias de transporte marítimo e de terminais, investimentos a serem realizados, fiscalização e liberdade de concorrência (muitas vezes os grandes armadores e os operadores logísticos pressionam o poder público no sentido de evitar a atuação de novas empresas no setor).

A proposta de Rangel (2005) para as concessões de serviços públicos à iniciativa privada (Projeto de Lei n. 2.569/89) é pautada em um poder público capaz de impor e cobrar dos concessionários os objetivos estabelecidos em contrato. Entretanto, a lei geral que regulamentou as concessões de serviços públicos no Brasil (Lei n. 8.987/95) é contrária aos interesses nacionais e pautada no Estadomínimo. No modelo ideal de concessão de serviços públicos à iniciativa privada, o Estado adquire novas funções e responsabilidades, quais sejam: poder concedente e credor hipotecário, dizer como e onde investir e estabelecimento de metas de investimentos e dos preços das tarifas cobradas dos usuários (pedágios). As empresas concessionárias devem oferecer parte de seus bens em garantia (hipoteca) para que, em caso de descumprimento do contrato ou da falta de pagamento, o poder público possa tomá-los e, assim, evitar prejuízos.

A participação do capital privado no setor portuário impulsionada pela Lei 8.630/93 - fomentou a modernização setorial. Nos principais portos e terminais privados do país (Santos/SP, Rio de Janeiro/RJ, Paranaguá/PR, Itajaí/SC, Navegantes/SC, Itapoá/SC, Rio Grande/RS etc.), destacam-se os Ship Loaders automatizados, ${ }^{5}$ STS (Ship to Shore Crane) (portêineres ${ }^{6}$ ), RTG (Rubber Tyres Gantry) (transtêineres ${ }^{7}$ ), MHC

5 Ship Loaders são dutos com sistema de sucção que realizam o carregamento e o descarregamento dos navios graneleiros.

${ }^{6}$ Portêineres são grandes guindastes que retiram os contêineres dos pátios e os conduzem aos navios e vice versa. 
SILVEIRA, M.R. \& FELIPE JR., N.F. A dinâmica do transporte marítimo ... (Mobile Habour Crane) (guindastes), Reach Stackers ${ }^{8}$, Terminal Tractors $^{9}$, softwares (Cosmos e Navys ${ }^{10}$ ), scanners ${ }^{11}$, contêineres especializados para cada tipo de mercadoria (carga seca, carga líquida e frigoríficos), navios Full Containers ${ }^{12}$, graneleiros (granéis sólidos) e mistos (líquidos e sólidos) de grande capacidade e sistema ISPS Code (maior segurança no porto - câmeras e controle de pessoas, veículos e cargas).

Os navios porta-contêineres utilizados nas rotas marítimas entre o Brasil e o exterior estão cada vez maiores. Até o início da década de 2000, essas embarcações tinham capacidade para transportar 2,5 mil TEUs. Em 2010, a Hamburg Süd e a Maersk colocaram em operação nas linhas que servem o Brasil os primeiros de uma série de navios entre 7 mil e 9,6 mil TEUs. Em alguns portos europeus e asiáticos trafegam navios de 12 mil e 15 mil TEUs.

Uma importante inovação tecnológica no setor marítimo mundial e brasileiro é o navio E-Ship 1 - navio cargueiro movido a energia eólica. Além da força dos ventos, usa motores a diesel e eletricidade. $\mathrm{O}$ navio possui quatro grandes rotores cilíndricos instalados no convés principal que giram, e esses movimentos, juntamente ao efeito do vento lateral, criam uma força que ajuda a impulsionar a embarcação. Essa tecnologia permite uma economia de combustível de $30 \%$ a $40 \%$.

${ }^{7}$ Transtêineres são guindastes que movimentam os contêineres nos pátios dos terminais.

8 Reach Stackers são empilhadeiras e veículos especiais para movimentação de contêineres.

9 Terminal Tractors são caminhões para movimentação de contêineres nos terminais.

${ }^{10}$ Os softwares Cosmos e Navys realizam o controle de todas as operações realizadas nos terminais e fornecem as informações em tempo real (real time).

${ }^{11}$ Scanners são utilizados para fiscalização e controle das mercadorias conteinerizadas.

12 Full Containers são navios especializados no transporte de bens acondicionados. 
SILVEIRA, M.R. \& FELIPE JR., N.F. A dinâmica do transporte marítimo ...

Devido à recessão econômica internacional, $5 \%$ da frota mundial de navios estão parados e este fato, por sua vez, resultou em uma queda no preço do frete marítimo. Assim, os grandes armadores - caso da Maersk, Hamburg Süd e Mediterranean Shipping Company (MSC) estão adotando novas estratégias, caso da diminuição da oferta de navios para escoamento de cargas conteinerizadas, para induzir a um aumento relativo dos fretes. Os novos navios em circulação são maiores e menos poluentes. Além disso, as empresas estão realizando joints, ou seja, dois ou mais armadores estão transportando cargas em um mesmo navio, como forma de redução de custos e utilização da capacidade máxima dos grandes porta-contêineres.

A substituição de navios de médio porte por outros maiores induz ao aumento dos fluxos nos portos de maior calado e capacidade operacional. Essa estratégia reduz custos com tripulação, combustível e manutenção. Os grandes armadores estão priorizando as principais rotas, os mercados consumidores em expansão (Brasil, Índia e África do Sul) e os hub ports (portos concentradores).

No que se refere ao Programa de Aceleração do Crescimento (PAC) e, mais precisamente, ao PAC-portos, têm-se repercussões positivas (melhorias relativas nas infraestruturas e nas condições de navegação), todavia, a excessiva burocracia, a demora na liberação das verbas públicas, os embargos jurídicos e ambientais, os recursos insuficientes e a morosidade das obras impedem maiores avanços no setor.

Apesar da relativa modernização do setor portuário e marítimo brasileiro, há ainda diversos gargalos que prejudicam o desenvolvimento econômico nacional, quais sejam: os congestionamentos nos portos e nas vias rodoviárias de articulação, ineficácia das ligações ferroviárias, utilização demasiada do modal rodoviário para o transporte das cargas (importância do sistema intermodal, com maior utilização do modal ferroviário), falta de modernização tecnológica em alguns portos (instalações e equipamentos obsoletos), baixo calado, atrasos para atracação dos navios nos cais portuários, demora na liberação das cargas 
SILVEIRA, M.R. \& FELIPE JR., N.F. A dinâmica do transporte marítimo ...

(sobretudo de importação), espaços portuários obsoletos e ociosos (caso, por exemplo, do porto santista), necessidade de maior atuação estatal no sentido de impor metas de investimentos ao capital privado (mudança do modelo de concessões e arrendamentos portuários), problemas nas rodovias (má sinalização e asfaltamento), diferentes valores do Imposto sobre Circulação de Mercadorias e Serviços (ICMS) cobrados pelos estados (muitas vezes os proprietários das cargas e os transportadores optam por rotas mais longas para reduzir os custos com o tributo e, assim, atrasam na chegada aos portos) e ineficiência das instituições que atuam no setor portuário e marítimo (Agência Nacional de Transportes Aquaviários - ANTAQ, Secretaria de Portos - SEP, Companhias Docas, Autoridades Portuárias e Receita Federal).

\section{Considerações finais}

A formação de redes marítimas (cabotagem e longo curso) é basilar para o processo de reprodução do capital. O tempo de rotação do capital é acelerado com a otimização da logística e do sistema de transportes, em especial, do modal marítimo, mediante a utilização de navios e contêineres modernos, rapidez e eficiência no transbordo das cargas, vias de acesso fluidas aos portos litorâneos, utilização da multimodalidade/intermodalidade e calado profundo permitindo a atracação de grandes navios cargueiros. A expansão do transporte marítimo é essencial para o fomento do comércio exterior, das trocas nacionais e internacionais, das interações espaciais, da produção e dos serviços.

$\mathrm{O}$ transporte marítimo possui relação com as fases expansivas e recessivas da economia. Nos momentos ascendentes, aumenta-se o crédito, intensificam-se as inversões privadas na produção e na circulação, potencializam-se as trocas, eleva-se o emprego, a renda e o consumo e intensifica-se a demanda pelo escoamento de cargas em grandes navios. Entretanto, nos períodos de crise, há enfraquecimento da atividade produtiva, mitigação dos 
SILVEIRA, M.R. \& FELIPE JR., N.F. A dinâmica do transporte marítimo ...

fluxos de cabotagem e longo curso, elevação do desemprego e queda na renda e no consumo.

A expansão do transporte marítimo (cabotagem e longo curso) e das suas infraestruturas potencializa o desenvolvimento econômico, permite o suprimento da cadeia de fornecimentos (matérias-primas), fomenta a produção agropecuária e industrial, a extração de minérios e gera empregos e renda à população. Dessa maneira, é fundamental a transferência de recursos ociosos para o setor portuário e a existência de um modelo ideal de concessão de serviços públicos à iniciativa privada (proposta rangeliana), sendo vitais para reduzir os estrangulamentos na base material e promover o efeito multiplicador interno. Somam-se ainda, as estratégias de reserva de mercado, aumento das inversões públicas e privadas, expansão dos financiamentos e criação de armadores estatais (para beneficiar a indústria naval nacional).

Nos últimos anos houve uma recuperação relativa da economia brasileira, impulsionada pela expansão do crédito, pelos investimentos em fixos (Programa de Aceleração do Crescimento PAC) e pela expansão das trocas Sul-Sul. Tais medidas anticíclicas, com base no planejamento, criaram condições para a intensificação dos fluxos marítimos. Todavia, é fundamental o Estado promover a substituição de importações, especialmente nos segmentos industriais estratégicos (bens de capital e médio e elevado padrão tecnológico), para reduzir as compras externas, agregar valor às exportações nacionais e impulsionar o desenvolvimento econômico.

O sistema marítimo brasileiro é concentrado nos portos do Sul e do Sudeste, sendo responsáveis por grande parte das importações e exportações nacionais (longo curso) - granéis sólidos e líquidos e artigos industriais. O Porto de Santos/SP se destaca nos fluxos de bens industrializados e de contêineres (maior valor agregado), sendo um ponto nodal que atende a demanda, sobretudo, da macrometrópole (Região Metropolitana de São Paulo e seu entorno) e do interior do estado. Não obstante, seu campo de influência extrapola os limites do território paulista, pois é 
SILVEIRA, M.R. \& FELIPE JR., N.F. A dinâmica do transporte marítimo ...

responsável por parte das exportações e importações de diversos estados brasileiros (principalmente do Centro-Oeste), bem como de outros países, caso do Paraguai e da Bolívia.

O sistema marítimo brasileiro não é homogêneo. O Estado de Santa Catarina possui diversos portos e terminais privados que "dividem" relativamente a demanda (desconcentração portuária), com destaque aos complexos especializados na movimentação de cargas conteinerizadas (Itajaí/SC, Navegantes/SC e Itapoá/SC). No caso do Estado de São Paulo, verifica-se um processo diferente, pois existe uma grande concentração da movimentação de mercadorias no Porto de Santos/SP (granéis sólidos, granéis líquidos e carga geral). Casos similares ao paulista são observados nos estados do Paraná e Rio Grande do Sul, em que os portos de Paranaguá/PR e Rio Grande/RS concentram os fluxos marítimos de cargas conteinerizadas e não-conteinerizadas.

O processo de modernização do setor portuário e marítimo brasileiro possui duas características principais: a) sempre foi tardio em comparação às nações desenvolvidas (grande parte das inovações tem origem no centro do sistema capitalista); b) as inovações na circulação marítima ganharam relevância nas duas últimas décadas, visto que o mercado sul-americano e, especialmente o brasileiro, está obtendo maior destaque em âmbito internacional (incremento do consumo e da produção nos últimos anos).

Há uma modernização incompleta no setor portuário brasileiro. Apesar dos avanços serem relativos, menos significativos em comparação aos principais portos do mundo, houve um aumento no nível de competitividade e eficiência das operações portuárias, com incorporação de novas tecnologias (equipamentos e softwares). As transformações no sistema portuário e marítimo brasileiro, juntamente à maior integração comercial e econômica do país, fomentaram as importações e exportações. Modernos terminais, como o da Santos Brasil e Libra (em Santos/SP), APM Terminals, Portonave e Itapoá (em Santa Catarina), Wilson, Sons (em Rio Grande/RS) e Tecon (em Paranaguá/PR) são imprescindíveis para a dinâmica 
SILVEIRA, M.R. \& FELIPE JR., N.F. A dinâmica do transporte marítimo ...

macroeconômica, com destaque à utilização de Ship Loaders, portêineres, transtêineres, Reach Stackers, Terminal Tractors, softwares Cosmos e Navys, scanners, contêineres para carga seca, carga líquida e reefers, navios porta-contêineres, graneleiros e mistos de grande capacidade e câmeras de vigilância.

\section{Referências bibliográficas}

BRASIL. Agência Nacional de Transportes Aquaviários (ANTAQ). Dados estatísticos. Brasília, 2011, 2012.

BRASIL. Companhia Docas do Estado de São Paulo (CODESP). Informações e dados estatísticos. Santos, 2011, 2012.

BRASIL. Companhia Docas de São Sebastião. Dados estatísticos. São Sebastião, 2011, 2012.

BRASIL. Ministério do Desenvolvimento, Indústria e Comércio Exterior. Secretaria de Comércio Exterior (SECEX). Brasília, 2011, 2012.

CHESNAIS, F. A mundialização do capital. São Paulo: Xamã, 1996.

CHOLLEY, A. Observações sobre alguns pontos de vista geográficos. In. Boletim Geográfico. Ano XXII, n. 179 e 180. Rio de Janeiro: IBGE, 1964.

MAMIGONIAN, A. Kondratieff, ciclos médios e organização do espaço. In: Geosul, v. 14, n. 18. Universidade Federal de Santa Catarina (UFSC). Florianópolis, 1999, p. 152-157.

MARX, K. O capital: crítica da economia política (Livros 1 e 2). Rio de Janeiro: Civilização Brasileira, 2005.

MIGLIOLI, J. Acumulação de capital e demanda efetiva. São Paulo: Hucitec, 2004. 
SILVEIRA, M.R. \& FELIPE JR., N.F. A dinâmica do transporte marítimo ...

RANGEL, I. A história da dualidade brasileira. In: Revista de Economia Política, v. 1, n. 4. São Paulo, 1981.

RANGEL, I. Obras reunidas (vol. 1 e 2). Rio de Janeiro: Contraponto, 2005.

SANTOS, M. A natureza do espaço: técnica e tempo, razão e emoção. São Paulo: Edusp, 2002.

SILVEIRA, M. R. (Org.). Circulação, transportes e logística: diferentes perspectivas. São Paulo: Outras Expressões, 2011.

Recebido em março de 2013 Aceito em junho 2013 